\title{
Early Cardiac Injury in Acute Respiratory Distress Syndrome: Comparison of Two Experimental Models
}

\author{
Pavol MIKOLKA ${ }^{1,2}$, Petra KOSUTOVA ${ }^{1,2}$, Sona BALENTOVA ${ }^{3}$, Daniel CIERNY ${ }^{4}$, Jana \\ KOPINCOVA $^{2}$, Maros KOLOMAZNIK ${ }^{1,2}$, Marian ADAMKOV ${ }^{3}$, Andrea CALKOVSKA ${ }^{1,2}$, \\ Daniela MOKRA ${ }^{1,2}$
}

${ }^{1}$ Biomedical Center Martin, Jessenius Faculty of Medicine in Martin, Comenius University in Bratislava, Martin, Slovak Republic, ${ }^{2}$ Department of Physiology, Jessenius Faculty of Medicine in Martin, Comenius University in Bratislava, Martin, Slovak Republic, ${ }^{3}$ Department of Histology and Embryology, Jessenius Faculty of Medicine in Martin, Comenius University in Bratislava, Martin, Slovak Republic, ${ }^{4}$ Department of Clinical Biochemistry, Jessenius Faculty of Medicine in Martin, Comenius University in Bratislava, University Hospital Martin, Martin, Slovak Republic

Received March 30, 2020

Accepted October 6, 2020

\begin{abstract}
Summary
Acute respiratory distress syndrome (ARDS) is characterized by diffuse lung damage, inflammation, oedema formation, and surfactant dysfunction leading to hypoxemia. Severe ARDS can accelerate the injury of other organs, worsening the patient's status. There is an evidence that the lung tissue injury affects the right heart function causing cor pulmonale. However, heart tissue changes associated with ARDS are still poorly known. Therefore, this study evaluated oxidative and inflammatory modifications of the heart tissue in two experimental models of ARDS induced in New Zealand rabbits by intratracheal instillation of neonatal meconium $(100 \mathrm{mg} / \mathrm{kg})$ or by repetitive lung lavages with saline (30 ml/kg). Since induction of the respiratory insufficiency, all animals were oxygen-ventilated for next $5 \mathrm{~h}$. Total and differential counts of leukocytes were measured in the arterial blood, markers of myocardial injury [(troponin, creatine kinase myocardial band (CK-MB), lactate dehydrogenase (LD)] in the plasma, and markers of inflammation [tumour necrosis factor (TNF)a, interleukin (IL)-6], cardiovascular risk [galectin-3 (Gal-3)], oxidative changes [thiobarbituric acid reactive substances (TBARS), 3-nitrotyrosine (3NT)], and vascular damage [receptor for advanced glycation end products (RAGE)] in the heart tissue. Apoptosis of heart cells was investigated immunohistochemically. In both ARDS models, counts of total leukocytes and neutrophils in the blood, markers of myocardial injury, inflammation, oxidative and vascular damage in the plasma and heart tissue, and heart cell apoptosis increased
\end{abstract}

compared to controls. This study indicates that changes associated with ARDS may contribute to early heart damage what can potentially deteriorate the cardiac function and contribute to its failure.

\section{Key words}

Acute respiratory distress syndrome • Cardiac injury • Oxidative stress • Inflammation • Apoptosis

\section{Corresponding author}

D. Mokra, Department of Physiology and Biomedical Center Martin, Jessenius Faculty of Medicine in Martin, Comenius University in Bratislava, Mala Hora 4C, SK-03601 Martin, Slovak Republic. E-mail: daniela.mokra@uniba.sk

\section{Introduction}

Acute respiratory distress syndrome (ARDS) represents a serious life-threatening situation with a mortality rate about $40 \%$ in adults, however, different forms of ARDS may manifest in all age groups including neonates (De Luca 2019). In spite of growing knowledge on ARDS, the treatment is only supportive, with protective ventilation by low tidal volumes and prone positioning as the only interventions minimizing iatrogenic effects and decreasing mortality (Silva et al. 2020). Nevertheless, even in patients who had survived 
ARDS, the long-term quality of life is adversely affected (Johnson and Matthay 2010). High mortality of ARDS and worsened quality of life may be also attributed to dysfunction of other organs (heart, liver, kidneys, brain etc.), which are hit secondarily in the primary lung injury.

ARDS could be initiated by direct lung injury (e.g. pneumonia, gastric contents aspiration, neardrowning, toxic inhalation) or indirectly due to nonpulmonary reasons (e.g. sepsis, multiple trauma, acute pancreatitis, blood transfusion) (Rocco and Pelosi 2008). Regardless of the site of injury, ARDS is a heterogeneous syndrome with deterioration and disruption of the lung endothelial and epithelial barriers leading to diffuse alveolar damage, increased vascular permeability, and pulmonary oedema formation (Pierrakos et al. 2012). Dysfunction of alveolar-capillary lining enables excessive transepithelial migration and activation of neutrophils with release of toxic mediators, including proteases, reactive oxygen and nitrogen species (RONS), proinflammatory cytokines, and pro-coagulant molecules (Zemans et al. 2009). Deterioration of pulmonary surfactant together with oedema formation, ventilationperfusion mismatch, and inflammation lead to reduced lung compliance and hypoxemia (Pierrakos et al. 2012, Zebialowicz Ahlstrom et al. 2019).

However, ARDS affects not only the alveolar compartment but also the pulmonary circulation and, thereby, may negatively influence the hemodynamics and cardiac function, especially of the right ventricle. Mean pulmonary artery pressure may increase in ARDS as a consequence of structural alteration of the pulmonary circulation, with inflammation, vasoconstriction, oedema, thrombi, and vascular remodelling leading to excessive muscularization of pulmonary arteries (Moloney and Evans 2003). However, elevation in pulmonary artery pressure may be also caused by unadapted positive pressure ventilation, e.g. in the use of positive endexpiratory pressure (PEEP) $>10 \mathrm{~cm} \mathrm{H}_{2} \mathrm{O}$ (equal to $1.0 \mathrm{kPa}$ ), when alveolar distending pressure reduces the flow in the pulmonary capillaries (Repesse et al. 2015). Pulmonary vascular dysfunction defined by an elevated transpulmonary pressure gradient (pulmonary artery diastolic pressure minus pulmonary capillary wedge pressure) may induce acute cor pulmonale, which occurs in $>70 \%$ of cases of ARDS and contributes to increased mortality (Bull et al. 2010, Repesse et al. 2015).

Additional deterioration of extra-pulmonary organs including heart in ARDS can be associated with lung tissue injury, excessive and/or prolonged activation of neutrophils, increased apoptosis of lung cells, and systemic inflammatory response. Numerous potentially injurious products, such as pro-inflammatory cytokines, RONS, components of complement, as well as extracellular histones, heat-shock proteins and other damage-associated molecular patterns (DAMPs), released from the affected lung through injured alveolar-capillary membrane into the circulation could contribute to multiorgan failure (MOF) (Slutsky and Tremblay 1998, Ranieri et al. 1999, Plotz et al. 2004). Loss of integrity of alveolar-capillary membrane could be further worsened by excessive mechanical ventilation, contributing to decompartmentalization of the inflammatory response and spreading injury from the lung to the distal organs (Del Sorbo and Slutsky 2011).

Thus, there is a strong evidence that ARDS can ultimately affect the heart function. However, extent of deterioration of the heart tissue and relationship between the ARDS and direct cardiac injury have not been fully explained. Therefore, this study evaluated effects of direct lung injury induced in rabbits by intratracheal neonatal meconium instillation (meconium-induced model of ARDS) or repetitive saline lung lavage (surfactant-depleted model of ARDS) on the heart presented as changes in inflammatory, oxidative and vascular damage markers, and apoptotic markers in the heart tissue, and as changes in the plasma markers of myocardial injury.

\section{Methods}

\section{Animal instrumentation}

This study was authorized by the National Veterinary Board of Slovak Republic and the local Ethics Committee of Jessenius Faculty of Medicine in Martin. Adult New Zealand white rabbits of both genders with a body weight (b.w.) of $2.3 \pm 0.3 \mathrm{~kg}$ were instrumented in accordance with previous studies (Kosutova et al. 2016, Mikolka et al. 2018). The animals were sedated by infusion of anesthetics (tiletamine and zolazepam, $10 \mathrm{mg} / \mathrm{kg} / \mathrm{h}$ i.v.) and paralyzed with pipecuronium bromide $(0.3 \mathrm{mg} / \mathrm{kg} / 0.5 \mathrm{~h})$. Subsequently, animals were ventilated (Aura V, Chirana, Slovakia) with tidal volume $\left(\mathrm{V}_{\mathrm{T}}\right)$ of $6 \mathrm{ml} / \mathrm{kg}$, time of inspiration (Ti) $50 \%$, respiratory rate (RR) of 40 breaths $/ \mathrm{min}$, fraction of inspired oxygen $\left(\mathrm{FiO}_{2}\right)$ of 1.0 , and PEEP of $0.5 \mathrm{kPa}$. The animals were euthanized by an overdose of anaesthetics.

Gas exchange and acid-base balance were measured in arterial blood samples using analyser 
RapidLab TM348 (Siemens AG, Germany). The following parameters were calculated: $\mathrm{P} / \mathrm{F}=$ calculated as a ratio between arterial oxygen partial pressure $\left(\mathrm{PaO}_{2}\right)$ and fraction of inspired oxygen $\left(\mathrm{FiO}_{2}\right)$; oxygenation index $(\mathrm{OI})=\left(\right.$ mean airway pressure $\left.\times \mathrm{FiO}_{2}\right) / \mathrm{PaO}_{2}$; and alveolar-arterial gradient $(\mathrm{AaG})=\left[\mathrm{FiO}_{2}\left(\mathrm{P}_{\mathrm{atm}}-\mathrm{P}_{\mathrm{H} 2 \mathrm{O}}\right)-\right.$ $\left.\mathrm{PaCO}_{2} / 0.8\right]-\mathrm{PaO}_{2}$.

\section{Experimental models of ARDS}

After $15 \mathrm{~min}$ of stabilisation, animals were randomly divided into 3 groups $(\mathrm{n}=7$ for each): (i) Control group, healthy ventilated controls without any other intervention; (ii) ARDS-MAS, meconium-induced ARDS; (iii) ARDS-LAV, surfactant-depleted ARDS.

Meconium-induced model of ARDS (ARDSMAS), mimicking the neonatal meconium aspiration syndrome, was induced by intratracheal instillation of meconium suspension $(4 \mathrm{ml} / \mathrm{kg})$ in semi-upright lateral positions of animal to supply a homogenous distribution of meconium throughout the lungs (Mikolka et al. 2018). First-pass meconium was obtained from 25 healthy term neonates born in University Hospital (Martin, Slovakia), then lyophilized and suspended in saline $(25 \mathrm{mg} / \mathrm{ml})$.

Surfactant-depleted model of ARDS (ARDSLAV) was induced by repeated lung lavage with saline $\left(30 \mathrm{ml} / \mathrm{kg}, 37^{\circ} \mathrm{C}\right)$ with $2 \mathrm{~min}$ intervals of ventilation between the lavages (Kosutova et al. 2016).

For both models, respiratory failure was defined as a decrease of $\mathrm{P} / \mathrm{F}<26.7 \mathrm{kPa}$, what equals moderate ARDS. After the criteria of lung injury were fulfilled, all animals were oxygen-ventilated $\left(\mathrm{V}_{\mathrm{T}} 6 \mathrm{ml} / \mathrm{kg}\right.$, Ti $50 \%$, $\mathrm{RR} 40 / \mathrm{min}, \mathrm{FiO}_{2} 1.0$, PEEP $0.5 \mathrm{kPa}$ ) for additional $5 \mathrm{~h}$.

Total and differential leukocyte counts in the arterial blood

Total leukocyte count was determined microscopically in a counting chamber after staining by Türck and expressed in absolute values. Differential leukocyte counts were estimated microscopically after staining by May-Grünwald/Giemsa-Romanowski and expressed as percentage (\%).

\section{Post-mortem tissue sampling and assays}

At the end of experiment, arterial blood was taken and centrifuged (3000 rpm, $15 \mathrm{~min}, 4{ }^{\circ} \mathrm{C}$ ) for plasma collection. The thorax was opened and the heart was excised. Tissue samples from right ventricle were either immediately shock frozen and stored at $-70{ }^{\circ} \mathrm{C}$ until biochemical analyses were performed, or fixed in
$10 \%$ buffered formalin.

In the heart homogenate prepared as $10 \%$ (weight/volume) tissue homogenate, oxidative modification was determined using OxiSelect $^{\mathrm{TM}}$ Nitrotyrosine ELISA Kit for proteins and OxiSelect ${ }^{\mathrm{TM}}$ TBARS Assay Kit for lipids (both Cell Biolabs Inc., USA). ELISA assays were also used for determination of damage to the heart endothelial cells (receptor for advanced glycation end products (RAGE), MyBioSource, USA), tumor necrosis factor alpha (TNF $\alpha$ ), interleukine-6 (IL-6; both Cloud-Clone Corp., USA) and galectin-3 (GAL-3; BlueGene, China). The plasma markers of myocardial injury: cardiac troponin $\mathrm{T}$ ( $\mathrm{cTnT}$ ), $\mathrm{MB}$ fraction of creatine kinase (CK-MB), and lactate dehydrogenase (LD) were determined using standard biochemical analysers (Olympus AU640/AU680, Mitsubishi Pathfast). Levels of lactate in plasma was determinated using lactate meter (Statsensor Novavet, NOVA Biomedical, USA).

In situ labeling of DNA strand breaks by TUNEL method was performed on paraffin embedding microtome slides from the formalin fixed heart samples using DeadEnd ${ }^{\mathrm{TM}}$ Colorimetric TUNEL System (Promega, USA). For immunohistochemical investigation of activated caspase- 3 in the heart, primary antibody rabbit anti-caspase 3 (1:500; Bioss, USA), subsequently biotinylated anti-rabbit secondary antibody and peroxidase-labelled streptavidin conjugated to HRP (DAKO LSAB®2 System-HRP; Dako, Denmark) were used. For both analyses, the count of affected cells was calculated from three sites within each section as described previously (Kosutova et al. 2018).

\section{Statistical analysis}

Statistical analysis was performed using statistic software Graph Pad Prism 8 (USA). The differences among the groups were analysed by Kruskal-Wallis nonparametric test with Dunn's multiple all pairs comparison test. A $p<0.05$ was considered for statistically significant. The results are presented as means \pm SD.

\section{Results}

\section{Lung function parameters}

Induction of lung injury using both insults, meconium instillation (ARDS-MAS) or lung lavage (ARDS-LAV), led to a significant worsening in the lung function parameters (Table 1). In both models, all respiratory parameters; $\mathrm{P} / \mathrm{F}$ ratio, oxygenation index (OI), 
and alveolar-arterial gradient (AaG) were deteriorated and reached the pre-determined limit for ARDS $(\mathrm{P} / \mathrm{F}<26.7 \mathrm{kPa})$ compared to controls, while this deterioration persisted till the end of experiment (ARDS-
MAS \& ARDS-LAV vs. Control $p<0.001)$. Significant differences between the models were observed in $\mathrm{P} / \mathrm{F}$ and OI, with worse oxygenation in ARDS-MAS model (Table 1).

Table 1. Respiratory parameters: the ratio of arterial oxygen partial pressure to fraction of inspired oxygen (P/F), oxygenation index (OI), alveolar-arterial gradient (AaG), and pH before (basal value, BV) and after induced ARDS (Model) and within $5 \mathrm{~h}$ in Control group, meconium-induced (ARDS-MAS) and lavage-induced (ARDS-LAV) acute respiratory distress syndrome (ARDS) models.

\begin{tabular}{|c|c|c|c|c|c|c|c|c|}
\hline & BV & Model & $30^{\prime}$ & $1 \mathrm{~h}$ & $2 \mathrm{~h}$ & $3 \mathrm{~h}$ & $4 \mathrm{~h}$ & $5 \mathrm{~h}$ \\
\hline \multicolumn{9}{|l|}{$\boldsymbol{P} / \boldsymbol{F}(k P a)$} \\
\hline Control & $78.8 \pm 2.7$ & $81.2 \pm 5.7$ & $82.1 \pm 6.0$ & $82.1 \pm 5.8$ & $87.4 \pm 4.6$ & $86.4 \pm 3.1$ & $81.0 \pm 8.3$ & $81.0 \pm 4.5$ \\
\hline$A R D S-M A S$ & $76.4 \pm 4.3$ & $6.9 \pm 1.4^{\varphi \dagger}$ & $8.6 \pm 1.7^{\varphi \dagger}$ & $7.6 \pm 1.5^{\varphi}$ & $7.9 \pm 1.0^{\varphi}$ & $7.4 \pm 1.3^{\varphi \dagger}$ & $6.4 \pm 0.9^{\varphi \dagger}$ & $7.0 \pm 1.0^{\varphi \dagger}$ \\
\hline$A R D S-L A V$ & $76.4 \pm 9.8$ & $14.9 \pm 3.8^{\varphi}$ & $14.9 \pm 6.1^{\varphi}$ & $12.0 \pm 4.2^{\varphi}$ & $11.5 \pm 5.4^{\varphi}$ & $15.8 \pm 6.7^{\varphi}$ & $15.9 \pm 7.2^{\varphi}$ & $14.3 \pm 7.0^{\varphi}$ \\
\hline \multicolumn{9}{|l|}{$O I$} \\
\hline Control & $1.0 \pm 0.1$ & $0.9 \pm 0.1$ & $0.9 \pm 0.1$ & $0.9 \pm 0.1$ & $0.8 \pm 0.1$ & $0.8 \pm 0.1$ & $0.9 \pm 0.1$ & $0.8 \pm 0.1$ \\
\hline$A R D S-M A S$ & $0.8 \pm 0.2$ & $13.0 \pm 2.0^{\varphi \dagger \dagger}$ & $11.6 \pm 2.6^{\varphi \dagger \dagger}$ & $11.5 \pm 3.9^{\varphi}$ & $12.5 \pm 2.1^{\varphi \dagger}$ & $13.1 \pm 2.3^{\varphi \dagger \dagger}$ & $15.2 \pm 2.2^{\varphi \dagger \dagger \dagger}$ & $13.7 \pm 1.6^{\varphi^{\varphi \dagger \dagger}}$ \\
\hline$A R D S-L A V$ & $1.1 \pm 0.2$ & $7.8 \pm 1.9^{\varphi}$ & $8.0 \pm 3.2^{\varphi}$ & $10.0 \pm 5.3^{\varphi}$ & $9.6 \pm 4.3^{\varphi}$ & $7.9 \pm 2.5^{\varphi}$ & $8.0 \pm 3.2^{\varphi}$ & $8.7 \pm 1.2^{\varphi}$ \\
\hline \multicolumn{9}{|l|}{$\boldsymbol{A a G}(\mathrm{kPa})$} \\
\hline Control & $11.0 \pm 2.4$ & $8.3 \pm 5.7$ & $7.8 \pm 5.7$ & $7.7 \pm 5.7$ & $3.4 \pm 4.1$ & $3.7 \pm 2.8$ & $9.4 \pm 7.8$ & $5.2 \pm 2.8$ \\
\hline$A R D S-M A S$ & $10.6 \pm 0.7$ & $75.7 \pm 3.0^{\varphi}$ & $74.8 \pm 2.5^{\varphi}$ & $74.7 \pm 4.8^{\varphi}$ & $75.8 \pm 2.2^{\varphi}$ & $76.0 \pm 2.8^{\varphi}$ & $76.9 \pm 3.4^{\varphi}$ & $75.4 \pm 3.3^{\varphi}$ \\
\hline$A R D S-L A V$ & $12.9 \pm 1.1$ & $70.8 \pm 4.8^{\varphi}$ & $66.6 \pm 15.9^{\varphi}$ & $68.7 \pm 17.8^{\varphi}$ & $66.8 \pm 21.8^{\varphi}$ & $63.7 \pm 24.0^{\varphi}$ & $64.5 \pm 21.6^{\varphi}$ & $63.6 \pm 22.1^{\varphi}$ \\
\hline \multicolumn{9}{|l|}{$p H$} \\
\hline Control & $7.47 \pm 0.01$ & $7.42 \pm 0.02$ & $7.41 \pm 0.01$ & $7.37 \pm 0.01$ & $7.31 \pm 0.03$ & $7.28 \pm 0.02$ & $7.26 \pm 0.02$ & $7.25 \pm 0.02$ \\
\hline$A R D S-M A S$ & $7.48 \pm 0.02$ & $7.17 \pm 0.03^{\varphi}$ & $7.17 \pm 0.02^{\varphi}$ & $7.19 \pm 0.03^{\varphi}$ & $7.14 \pm 0.04^{\varphi}$ & $7.11 \pm 0.04^{\varphi}$ & $7.12 \pm 0.06^{\varphi}$ & $7.07 \pm 0.05^{\varphi}$ \\
\hline$A R D S-L A V$ & $7.55 \pm 0.01$ & $7.23 \pm 0.02^{\varphi}$ & $7.22 \pm 0.02^{\varphi}$ & $7.2 \pm 0.03^{\varphi}$ & $7.15 \pm 0.02^{\varphi}$ & $7.11 \pm 0.03^{\varphi}$ & $7.07 \pm 0.02^{\varphi}$ & $7.06 \pm 0.04^{\varphi}$ \\
\hline
\end{tabular}

Statistical comparisons: ARDS-MAS \& ARDS-LAV vs. Control: ${ }^{\boldsymbol{\Phi}} p<0.001$; ARDS-MAS vs. ARDS-LAV ${ }^{\dagger} p<0.05,{ }^{+\dagger} p<0.01,{ }^{+++} p<0.001$.

Markers of vascular, inflammatory and oxidative modifications in the heart tissue

For determination of the heart vascular damage, receptor for advanced glycation end products (RAGE) was analysed. Significantly increased levels of RAGE were observed in ARDS-MAS group $(p<0.01$ vs. Control), while just negligible increase was found in ARDS-LAV group ( $p>0.05$ vs. Control). Similarly, the concentration of galectin-3 (Gal-3), a marker of cardiovascular risk, elevated only in ARDS-MAS group $(p<0.05$ vs. Control). Pro-inflammatory cytokines TNF $\alpha$ and IL-6 increased in the heart tissue homogenates in both ARDS models compared to controls; for TNF $\alpha$ and IL-6, $p<0.05$ for both ARDS-MAS \& ARDS-LAV vs. Control. Oxidative damage to lipids expressed by TBARS was higher only in ARDS-MAS group compared to controls $(p<0.05)$. Oxidative damage to proteins expressed by $3 \mathrm{NT}$ increased in both models (for both $p<0.05$ vs. Control). There were no significant differences between the ARDS models (Fig. 1).

\section{Plasma markers of myocardial injury}

For determination of myocardial injury in the plasma, cardiac troponin $\mathrm{T}$ (cTnT); MB fraction of creatine kinase (CK-MB); and lactate dehydrogenase (LD) were analysed. Levels of these markers significantly increased in both ARDS models compared to controls except for CK-MB in ARDS-MAS group vs. controls (Fig. 2).

Lactate, markers of inflammatory and oxidative modifications in the plasma

The levels of plasma lactate elevated over time in both ARDS groups (BV vs. 300' after model induction $p<0.001)$, for ARDS-MAS also in 180' vs. BV $(p<0.01)$. At the end of experiment, lactate levels were significantly higher in both ARDS models compared to controls (for both $p<0.001$ ). Similarly to the heart tissue, inflammatory 
and oxidative markers elevated in the plasma, too. TNF $\alpha$ significantly increased only in ARDS-LAV group compared to controls $(p<0.05)$. TBARS as a marker of lipid oxidation elevated in ARDS-LAV group $(p<0.01)$ and $3 \mathrm{NT}$ as a marker of protein modification increased in ARDS-MAS group $(p<0.01)$ compare to controls. There were no significant differences between the ARDS groups (Fig. 3). a.



d.

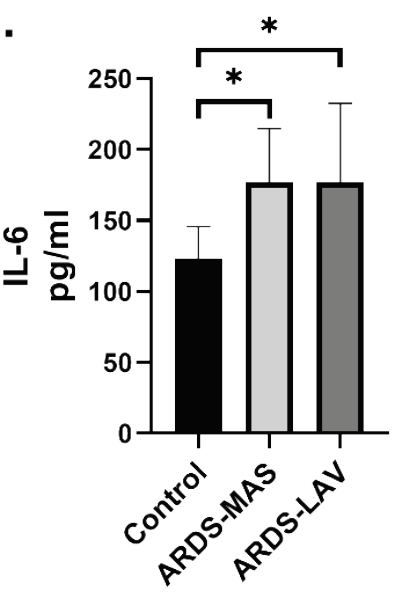

b.

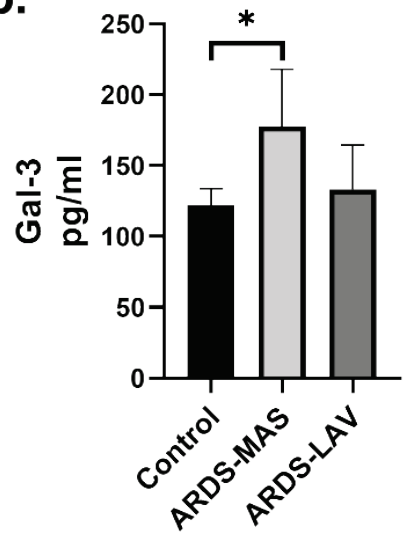

e.

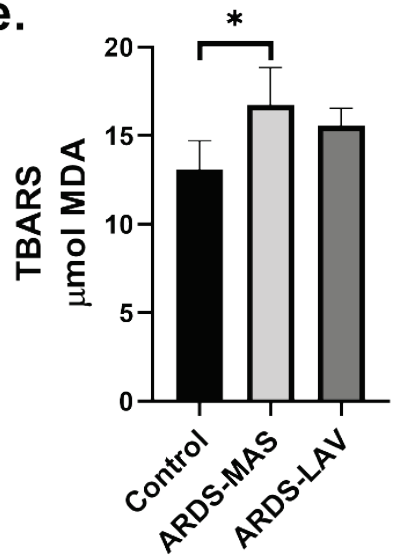

c.

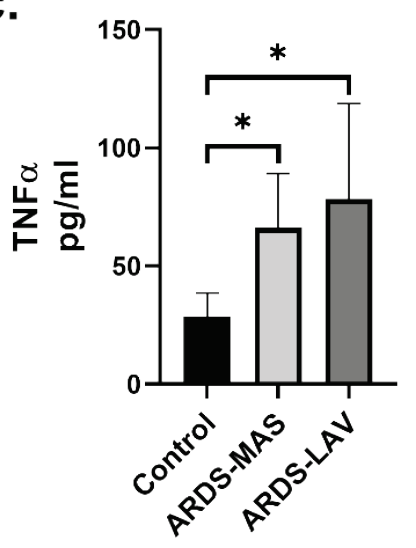

f.

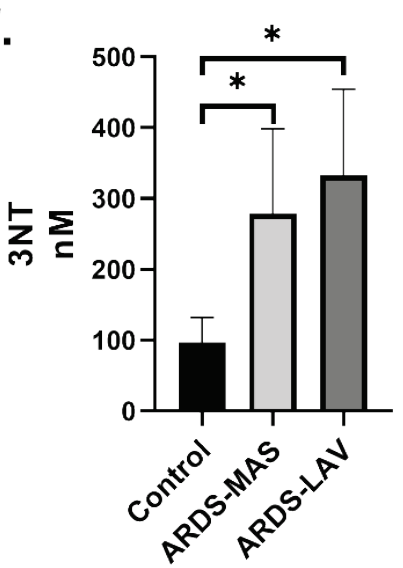

g.

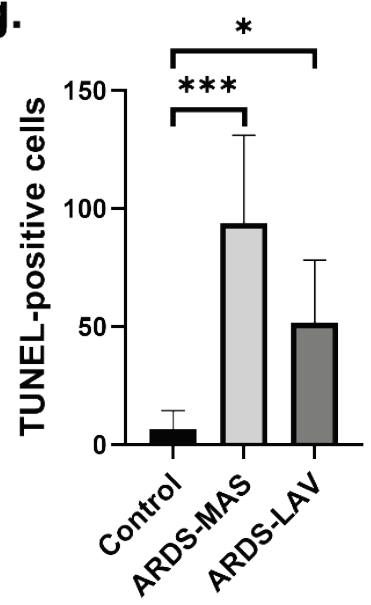

h.

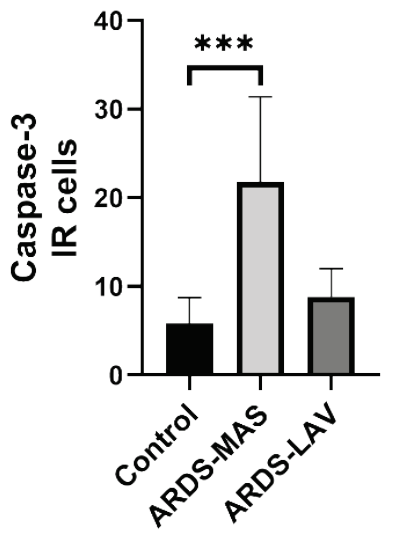

Fig. 1. Vascular damage, inflammatory, oxidative and apoptotic markers in the heart tissue in the control group, meconium-induced (ARDS-MAS) and lavage-induced (ARDS-LAV) acute respiratory distress syndrome (ARDS) models. (a) Receptor for advanced glycation end products (RAGE); (b) Galectin-3 (Gal-3); (c) Tumor necrosis factor alpha (TNFa); (d) Interleukin 6 (IL-6); (e) Thiobarbituric acidreactive substances (TBARS); (f) 3-nitrotyrosine (3NT); Number of (g) Terminal deoxynucleotidyl transferase-mediated dUTP nick end labeling (TUNEL)-positive cells and (h) Caspase-3 positive immunoreactive (IR) cells. Statistical comparisons: ARDS-MAS \& ARDS-LAV vs. Control: * $p<0.05, * * p<0.01$. 
a.

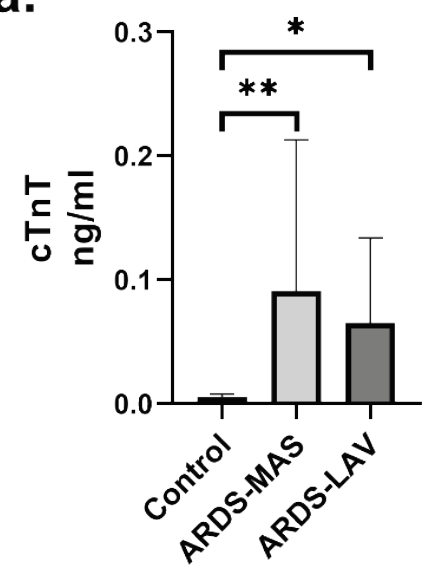

b.

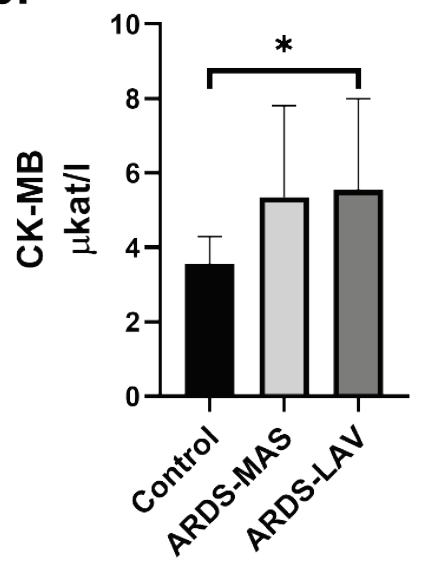

C.

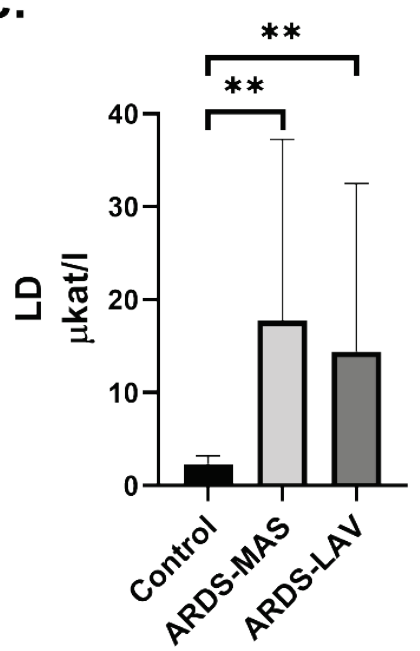

Fig. 2. The plasma markers of myocardial injury in the control group, meconium-induced (ARDS-MAS) and lavage-induced (ARDS-LAV) acute respiratory distress syndrome (ARDS) models. (a) Cardiac troponin T (cTnT); (b) Creatine kinase isoenzyme (CK-MB); (c) Lactate dehydrogenase (LD). Statistical comparisons: ARDS-MAS \& ARDS-LAV vs. Control: ${ }^{*} p<0.05, * * p<0.01$.

a.
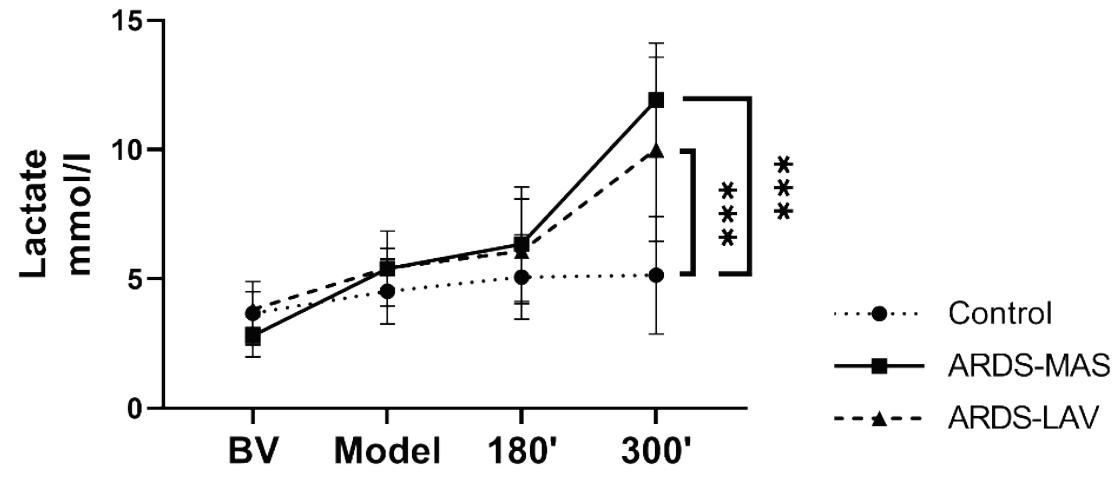

C.

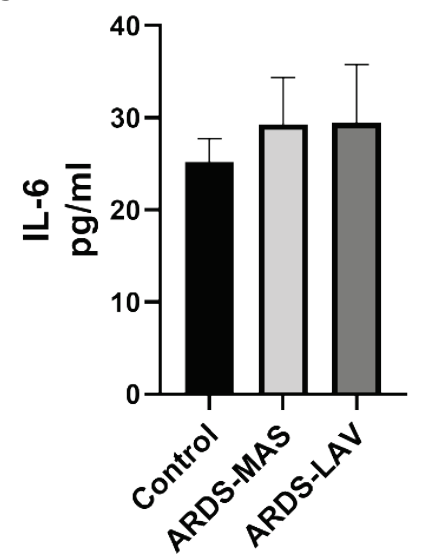

b.

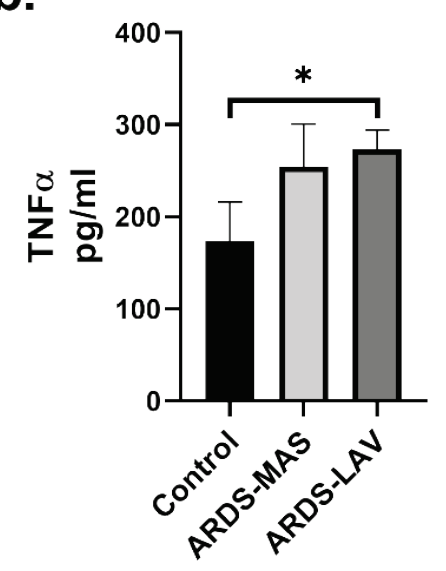

Fig. 3. Levels of lactate (a), inflammatory and oxidative markers in the plasma in the control group, meconium-induced (ARDS-MAS) and lavage-induced (ARDS-LAV) acute respiratory distress syndrome (ARDS) models. (b) Tumor necrosis factor alpha (TNFa); (c) Interleukin 6 (IL-6); (d) Thiobarbituric acid-reactive substances (TBARS); (e) 3-nitrotyrosine (3NT). Statistical comparisons: ARDS-MAS \& ARDS-LAV vs. Control: $* p<0.05, * * p<0.01, * * * p<0.001$. 
Apoptosis of the heart cells

The number of TUNEL-positive cells in the heart tissue significantly increased in both ARDS models with more obvious increase in ARDS-MAS group vs. controls $(p<0.001)$. Similarly, number of caspase-3 immunoreactive cells massively elevated in ARDS-MAS group compared to Control group $(p<0.001)$ (Fig. 1g, h).

Total and differential leukocyte counts in the arterial blood

As shown in Table 2, total leukocytes decreased with time in both ARDS models compared to controls. More potent effect was observed in ARDS-MAS group with a significant decrease of leukocytes already at $30 \mathrm{~min}$ after model induction compared to controls $(p<0.05)$ and this change had gradually pronounced (at $5 \mathrm{~h}$ for ARDS-MAS vs. Control $p<0.001$ ). Significant differences in the neutrophil percentages for baseline values vs. values at the end of the experiment in Control $(p<0.05)$ and in both ARDS-MAS and ARDS-LAV groups (for both $p<0.001$ ) were observed (Table 1).

Table 2. Total and differential leukocyte counts in the arterial blood before (basal value, BV) and within $5 \mathrm{~h}$ after induced ARDS ('hit') in Control group, meconium-induced (ARDS-MAS) and lavage-induced (ARDS-LAV) acute respiratory distress syndrome (ARDS) models.

\begin{tabular}{|c|c|c|c|c|}
\hline & & Control & ARDS-MAS & ARDS-LAV \\
\hline \multicolumn{5}{|c|}{ Total count of leukocytes $\left(\times 10^{-9}\right)$} \\
\hline & BV & $2.69 \pm 0.23$ & $2.50 \pm 0.19$ & $2.30 \pm 0.19$ \\
\hline & $30^{\prime}$ hit & $2.26 \pm 0.29$ & $1.67 \pm 0.18^{*}$ & $2.47 \pm 0.27$ \\
\hline & $1 \mathrm{~h}$ hit & $2.50 \pm 0.26$ & $1.28 \pm 0.08 * * *$ & $2.04 \pm 0.24 *$ \\
\hline & $3 \mathrm{~h}$ hit & $2.14 \pm 0.23$ & $1.31 \pm 0.10^{* *}$ & $1.61 \pm 0.15^{*}$ \\
\hline & 5 h hit & $2.37 \pm 0.36$ & $1.10 \pm 0.10 * * *$ & $1.73 \pm 0.20 * *$ \\
\hline \multicolumn{5}{|c|}{ Differential count (\%) } \\
\hline \multirow{2}{*}{$\mathrm{Neu}(\%)$} & $\mathrm{BV}$ & $2.35 \pm 1.09$ & $2.06 \pm 0.60$ & $2.65 \pm 0.78$ \\
\hline & 5 h hit & $21.46 \pm 7.45^{\dagger}$ & $28.19 \pm 3.04^{\dagger \dagger \dagger}$ & $30.66 \pm 3.28^{\dagger \dagger \dagger}$ \\
\hline \multirow{2}{*}{$\operatorname{Lym}(\%)$} & BV & $91.14 \pm 4.70$ & $95.58 \pm 0.99$ & $95.46 \pm 0.91$ \\
\hline & 5 h hit & $76.12 \pm 7.67$ & $70.99 \pm 2.84$ & $71.35 \pm 3.34$ \\
\hline \multirow{2}{*}{ Mono (\%) } & BV & $1.47 \pm 0.17$ & $1.64 \pm 0.23$ & $1.19 \pm 0.11$ \\
\hline & 5 h hit & $1.31 \pm 0.19$ & $1.41 \pm 0.15$ & $0.90 \pm 0.09$ \\
\hline \multirow{2}{*}{$\operatorname{Eos}(\%)$} & BV & $0.51 \pm 0.16$ & $0.69 \pm 0.35$ & $0.69 \pm 0.21$ \\
\hline & 5 h hit & $0.49 \pm 0.01$ & $0.46 \pm 0.11$ & $0.37 \pm 0.09$ \\
\hline
\end{tabular}

Neutrophils (Neu), Lymphocytes (Lym), Monocytes (Mono), Eosinophils (Eos). Significant comparisons: ARDS-MAS \& ARDS-LAV vs. Control: * $p<0.05, * * p<0.01 ; * * * p<0.001$; BV vs. 5 h hit: ${ }^{+} p<0.05,{ }^{+t+} p<0.001$.

\section{Discussion}

ARDS is associated with a diffuse alveolar epithelial and endothelial damage leading to surfactant alteration, oedema formation, ventilation-perfusion mismatch, and inflammation. This leads to reduced lung compliance and profound hypoxemia (Pierrakos et al. 2012, (Hernandez-Beeftink et al. 2019, Mikolka et al. 2019). Current treatment of ARDS is mainly supportive with emphasis on management of hypoxemia using lungprotective ventilation (Confalonieri et al. 2017). Mechanical ventilation could contribute to spreading of acute-phase reactants from the lung to peripheral circulation, and together with action of activated neutrophils, could target the extra-pulmonary organs and contribute to multiple organ failure (MOF) (Plotz et al. 2004, Zemans et al. 2009, Del Sorbo and Slutsky 2011, Grommes and Soehnlein 2011). Moreover, pulmonary vascular injury in ARDS has direct impact on the heart, affecting hemodynamics and function of the right ventricle (Repesse et al. 2015). Because the mechanisms and time relations of the heart injury secondary to ARDS need to be elucidated, the present study has focused on direct changes in the heart tissue associated with two 
experimental models of ARDS, surfactant-depleted model of ARDS (ARDS-LAV) and meconium-induced model of ARDS (ARDS-MAS). However, meconium aspiration syndrome in the text should be treated with caution, because adult rabbits with the associated limitation were used. We expect, that effect of hypoxia induced by meconium-induced lung injury on heart tissue was observed. And the same effect may vary in the neonatal heart. Used adult animals avoided postnatal changes of the lung, heart and hemodynamics. Due to ethical and technical problems with instrumentation of the neonatal animals, use of adult animals is preferred, especially in the studies where artificial ventilation is used (Calkovska et al. 2008, Kopincova et al. 2018). In addition, some inter-species differences in the immune system between humans and animals may result in some differences in response to induction of the model and effect on heart tissue. Considering all limitations, using the rabbit provides an animal model that resembles humans in anatomical structure (Kamaruzaman et al. 2013) and we feel that the results of our study bring new information for research on ARDS.

The main hallmark of ARDS is diffuse alveolar damage resulting in respiratory failure. In this study, situation resembling ARDS was induced by two approaches: intratracheal instillation of meconium or repeated lung lavage with saline. Both interventions led to deterioration of the lung function parameters $(\mathrm{P} / \mathrm{F}, \mathrm{OI}$ and $\mathrm{AaG}$ ) which occurred within several minutes and remained stable until the end of experiment, in agreement with previous studies (Kamiyama et al. 2015, Ricci et al. 2017). Instillation of meconium showed more negative impact on the respiratory parameters compared to lung lavages, while at some timepoints the differences for $\mathrm{P} / \mathrm{F}$ and OI between the ARDS models were significant. This finding is consistent with previous experience that aspiration of neonatal meconium cause severe ARDS (Szymankiewicz et al. 2004, Mikolka et al. 2018, Thomas et al. 2018). Reduced amount of oxygen in the blood (hypoxemia), clearly visible at the $\mathrm{P} / \mathrm{F}$ ratio in both ARDS models, leads to tissue hypoxia which can rapidly progress to MOF and death (Bakker et al. 1996, Kamo et al. 2019). Measurement of blood lactate concentration has been used for monitoring tissue oxygenation, because cells deprived of adequate oxygen produce excessive quantities of lactate. Finding of significantly increased lactate in both ARDS models vs. Control in our study indicates serious tissue hypoxia in these lung-injured animals.
In response to the lung injury, neutrophils are rapidly recruited into the lung (Grommes and Soehnlein 2011). In our study, increased percentage of neutrophils at $5 \mathrm{~h}$ vs. BV was observed also in Controls where it could attribute to neutrophil demarginalization due to anaesthesia, surgical interventions, and mechanical ventilation. However, in ARDS groups the increase in neutrophils was more remarkable and was associated with gradual decrease in a total count of leukocytes, confirming transmigration of neutrophils into the lung.

After activation, neutrophils release various bioactive agents into the lung tissue as well as into the systemic circulation, such as chemokines, proinflammatory cytokines, acute-phase reactants, matrix remodelling enzymes, and reactive oxygen species (ROS) through their oxidant-generating systems comprising the phagocyte NADPH oxidase and nitric oxide synthase (Grommes and Soehnlein 2011, Parekh et al. 2011). In our study, significantly increased protein nitrosylation (3NT) in ARDS-MAS group and lipid peroxidation (TBARS) in ARDS-LAV group were observed in the plasma and heart tissue compared to Control. These findings are in agreement with other authors ( $\mathrm{Li}$ et al. 2013, Antonucci et al. 2014, Lv and Wang 2016), who confirmed relation between ARDS- or sepsis-induced oxidation stress with myocardial mitochondrial damage.

Inflammatory processes in ARDS can multiply the oxidative stress with ROS overproduction (Tasaka et al. 2008, Confalonieri et al. 2017) and vice versa. In this study, pro-inflammatory cytokines TNF $\alpha$ and IL-6 were evaluated as biomarkers of early phase of ARDS (Mokra and Kosutova 2015). TNF $\alpha$ mediates various acute and chronic inflammatory reactions such as systemic inflammation or initiation of acute phase reaction, and along with IL-6 represent the key regulators of gene expression of acute phase proteins (Bavunoglu et al. 2016). However, increased concentrations of proinflammatory cytokines of the early phase are associated with greater mortality (Bhatia and Moochhala 2004, Del Sorbo and Slutsky 2011, Aisiku et al. 2016). In this study, plasma TNF $\alpha$ and IL-6 increased in both ARDS groups compared to Control with statistical significance only for TNF $\alpha$ in ARDS-LAV, what is consistent with our previous studies (Kosutova et al. 2018, Mikolka et al. 2019). In the heart tissue, levels of TNF $\alpha$ and IL-6 significantly increased in both ARDS models compared to controls. In accordance with cytokines, other inflammatory marker galectin-3 (Gal-3) significantly elevated in the heart tissue homogenate in 
ARDS-MAS model vs. controls. In the heart, Gal-3 regulated by paracrine signalization stimulates proliferation of myofibroblasts and accumulation of procollagen in the extracellular matrix, causing heart fibrosis what suggests galectin for a predictive marker of the heart failure (Suarez and Meyerrose 2014).

Spreading of inflammation markers by circulation can affect the endothelium of extra-pulmonary organs. Inflammatory stimuli can indirectly upregulate production of receptor for advanced glycation end products (RAGE) via NF- $\mathrm{BB}$ activation. Increased RAGE, as a result of vascular damage, maintains and amplifies inflammatory responses in the vasculature if ligand for the receptor is present. Interestingly, RAGE binding by circulating advanced glycation end products or S100 protein released by activated leukocytes results in the generation of ROS and further activation of NF- $\kappa B$. This leads to upregulation of adhesion molecules for circulating monocytes and further upregulation of RAGE itself (Farmer and Kennedy 2009). In our study, ARDS-induced inflammation led to overproduction of RAGE in the heart tissue with more serious changes in ARDS-MAS vs. Control. Activation of endothelium in distant organs was previously confirmed by increased expression of adhesion molecules (Hegeman et al. 2009).

Additional evidence of direct myocardial injury has been provided by increased plasma concentrations of cardiac specific troponin $\mathrm{N}$ (cTnT), creatine kinase isoenzyme MB (CK-MB) and lactate dehydrogenase (LD) in both ARDS-MAS and ARDS-LAV groups compared to controls. The cTnT levels are frequently elevated in patients with ARDS what is associated with adverse outcomes, including death, organ failure, and need for mechanical ventilation (Rivara et al. 2012). CK-MB and LD have been also widely used as clinical markers of cardiac injury or failure (Nigam 2007), Danese and Montagnana 2016). There are several mechanisms potentially contributing to myocardial injury: tissue hypoxia due to reduced coronary flow, cardiac depressant effects of ARDS-induced circulating pro-inflammatory mediators, nitric oxide, matrix metalloproteinases, mitogen-activated protein kinase activity, metabolic alterations including increased lactate, mitochondrial dysfunction or oxidative stress, induction of cell apoptosis leading to myocardial cell death etc. (Flierl et al. 2008). Increased apoptosis of myocardial cells as one of the reasons for direct heart injury was also found in our study, as indicated by increased number of apoptotic cells detected by TUNEL method and increased activation of caspase- 3 in the heart tissue of ARDS affected animals. These findings are in agreement with other authors (Li et al. 2013, Lv and Wang 2016).

Concluding, this study demonstrated significant inflammatory, oxidative and vascular modifications in the heart tissue in two distinct models of ARDS. Meconiuminduced lung injury (ARDS-MAS) had more serious impact and significantly affected more markers compared to surfactant-depleted lung injury (ARDS-LAV). We can speculate, that delivered meconium induced stronger respiratory failure and stronger inflammation process than lung lavage. Aspirated meconium triggers the inflammation via TLR4/MD-2 CD14 signaling complex (Salvesen et al. 2010) and is a rich source of cytokines (de Beaufort et al. 2003). Whereas these changes occurred very early, at $5 \mathrm{~h}$ after induction of experimental ARDS, potential functional and morphological changes of the heart should be considered, because they can influence the status and future prognosis of patients. However, further investigation is warranted to define the relationship between ARDS and early myocardial injury more in detail.

\section{Conflict of Interest}

There is no conflict of interest.

\section{Acknowledgements}

The authors thank D. Kuliskova, Z. Remisova, M. Hutko and M. Petraskova for technical assistance. This work was supported by projects APVV-15-0075, APVV-170250, VEGA 1/0356/18, VEGA 1/0055/19, and project "Biomedical Center Martin" (ITMS code 26220220187), co-financed from EU sources.

\section{References}

AISIKU IP, YAMAL JM, DOSHI P, BENOIT JS, GOPINATH S, GOODMAN JC, ROBERTSON CS: Plasma cytokines IL-6, IL-8, and IL-10 are associated with the development of acute respiratory distress syndrome in patients with severe traumatic brain injury. Crit Care 20: 288, 2016. https://doi.org/10.1186/s13054-016-1470-7

BAKKER J, GRIS P, COFFERNILS M, KAHN RJ, VINCENT JL: Serial blood lactate levels can predict the development of multiple organ failure following septic shock. Am J Surg 171: 221-226, 1996. https://doi.org/10.1016/S0002-9610(97)89552-9 
BAVUNOGLU I, GENC H, KONUKOGLU D, CICEKCI H, SOZER V, GELISGEN R, UZUN H: Oxidative stress parameters and inflammatory and immune mediators as markers of the severity of sepsis. J Infect Dev Ctries 10: 1045-1052, 2016. https://doi.org/10.3855/jidc. 7585

BHATIA M, MOOCHHALA S: Role of inflammatory mediators in the pathophysiology of acute respiratory distress syndrome. J Pathol 202: 145-156, 2004. https://doi.org/10.1002/path.1491

BULL TM, CLARK B, MCFANN K, MOSS M: Pulmonary vascular dysfunction is associated with poor outcomes in patients with acute lung injury. Am J Respir Crit Care Med 182: 1123-1128, 2010. https://doi.org/10.1164/rccm.201002-02500C

CALKOVSKA A, MOKRA D, DRGOVA A, ZILA I, JAVORKA K: Bronchoalveolar lavage with pulmonary surfactant/dextran mixture improves meconium clearance and lung functions in experimental meconium aspiration syndrome. Eur J Pediatr 167: 851-857, 2008. https://doi.org/10.1007/s00431-007-0596-7

CONFALONIERI M, SALTON F, FABIANO F: Acute respiratory distress syndrome. Eur Respir Rev 26: 2017. https://doi.org/10.1183/16000617.0116-2016

DE BEAUFORT AJ, BAKKER AC, VAN TOL MJ, POORTHUIS BJ, SCHRAMA AJ, BERGER HM: Meconium is a source of pro-inflammatory substances and can induce cytokine production in cultured A549 epithelial cells. Pediatr Res 54: 491-495, 2003. https://doi.org/10.1203/01.PDR.0000082017.97479.39

DE LUCA D: Personalising care of acute respiratory distress syndrome according to patients' age. Lancet Respir Med 7: 100-101, 2019. https://doi.org/10.1016/S2213-2600(18)30429-6

DEL SORBO L, SLUTSKY AS: Acute respiratory distress syndrome and multiple organ failure. Curr Opin Crit Care 17: 1-6, 2011. https://doi.org/10.1097/MCC.0b013e3283427295

FARMER DG, KENNEDY S: RAGE, vascular tone and vascular disease. Pharmacol Ther 124: 185-194, 2009. https://doi.org/10.1016/j.pharmthera.2009.06.013

FLIERL MA, RITTIRSCH D, HUBER-LANG MS, SARMA JV, WARD PA: Molecular events in the cardiomyopathy of sepsis. Mol Med 14: 327-336, 2008. https://doi.org/10.2119/2007-00130.Flierl

GROMMES J, SOEHNLEIN O: Contribution of neutrophils to acute lung injury. Mol Med 17: 293-307, 2011. https://doi.org/10.2119/molmed.2010.00138

HEGEMAN MA, HENNUS MP, HEIJNEN CJ, SPECHT PA, LACHMANN B, JANSEN NJ, VAN VUGHT AJ, COBELENS PM: Ventilator-induced endothelial activation and inflammation in the lung and distal organs. Crit Care 13: R182, 2009. https://doi.org/10.1186/cc8168

HERNANDEZ-BEEFTINK T, GUILLEN-GUIO B, VILLAR J, FLORES C: Genomics and the acute respiratory distress syndrome: current and future directions. Int J Mol Sci 20: 4004, 2019. https://doi.org/10.3390/ijms20164004

JOHNSON ER, MATTHAY MA: Acute lung injury: epidemiology, pathogenesis, and treatment. J Aerosol Med Pulm Drug Deliv 23: 243-252, 2010. https://doi.org/10.1089/jamp.2009.0775

KAMARUZAMAN NA, KARDIA E, KAMALDIN N, LATAHIR AZ, YAHAYA BH: The rabbit as a model for studying lung disease and stem cell therapy. Biomed Res Int 2013: 691830, 2013. https://doi.org/10.1155/2013/691830

KAMIYAMA J, JESMIN S, SAKURAMOTO H, SHIMOJYO N, ISLAM M, HAGIYA K, SUGANO M, UNOKI T, OKI M, KAWANO S, MIZUTANI T: Hyperinflation deteriorates arterial oxygenation and lung injury in a rabbit model of ARDS with repeated open endotracheal suctioning. BMC Anesthesiol 15: 73, 2015. https://doi.org/10.1186/s12871-015-0045-5

KAMO T, TASAKA S, SUZUKI T, ASAKURA T, SUZUKI S, YAGI K, NAMKOONG H, ISHII M, MORISAKI H, BETSUYAKU T: Prognostic values of the Berlin definition criteria, blood lactate level, and fibroproliferative changes on high-resolution computed tomography in ARDS patients. BMC Pulm Med 19: 37, 2019. https://doi.org/10.1186/s12890-019-0803-0

KOPINCOVA J, MIKOLKA P, KOLOMAZNIK M, KOSUTOVA P, CALKOVSKA A, MOKRA D: Modified porcine surfactant enriched by recombinant human superoxide dismutase for experimental meconium aspiration syndrome. Life Sci 203: 121-128, 2018. https://doi.org/10.1016/j.lfs.2018.04.036 
KOSUTOVA P, MIKOLKA P, BALENTOVA S, ADAMKOV M, KOLOMAZNIK M, CALKOVSKA A, MOKRA D: Intravenous dexamethasone attenuated inflammation and influenced apoptosis of lung cells in an experimental model of acute lung injury. Physiol Res 65 (Suppl 5): S663-S672, 2016. https://doi.org/10.33549/physiolres.933531

KOSUTOVA P, MIKOLKA P, KOLOMAZNIK M, BALENTOVA S, ADAMKOV M, CALKOVSKA A, MOKRA D: Reduction of lung inflammation, oxidative stress and apoptosis by the PDE4 inhibitor roflumilast in experimental model of acute lung injury. Physiol Res 67 (Suppl 4): S645-S654, 2018. https://doi.org/10.33549/physiolres.934047

MIKOLKA P, KOPINCOVA J, KOSUTOVA P, KOLOMAZNIK M, CALKOVSKA A, MOKRA D: Anti-IL-8 antibody potentiates the effect of exogenous surfactant in respiratory failure caused by meconium aspiration. Exp Lung Res 44: 40-50, 2018. https://doi.org/10.1080/01902148.2017.1420272

MIKOLKA P, KOSUTOVA P, KOLOMAZNIK M, TOPERCEROVA J, KOPINCOVA J, CALKOVSKA A, MOKRA D: Effect of different dosages of dexamethasone therapy on lung function and inflammation in an early phase of acute respiratory distress syndrome model. Physiol Res 68 (Suppl 3): S253-S263, 2019. https://doi.org/10.33549/physiolres.934364

MOKRA D, KOSUTOVA P: Biomarkers in acute lung injury. Respir Physiol Neurobiol 209: 52-58, 2015. https://doi.org/10.1016/j.resp.2014.10.006

MOLONEY ED, EVANS TW: Pathophysiology and pharmacological treatment of pulmonary hypertension in acute respiratory distress syndrome. Eur Respir J 21: 720-727, 2003. https://doi.org/10.1183/09031936.03.00120102

NIGAM PK: Biochemical markers of myocardial injury. Indian J Clin Biochem 22: 10-17, 2007. https://doi.org/10.1007/BF02912874

PAREKH D, DANCER RC, THICKETT DR: Acute lung injury. Clin Med (Lond) 11: 615-618, 2011. https://doi.org/10.7861/clinmedicine.11-6-615

PIERRAKOS C, KARANIKOLAS M, SCOLLETTA S, KARAMOUZOS V, VELISSARIS D: Acute respiratory distress syndrome: pathophysiology and therapeutic options. J Clin Med Res 4: 7-16, 2012. https://doi.org/10.4021/jocmr761w

PLOTZ FB, SLUTSKY AS, VAN VUGHT AJ, HEIJNEN CJ: Ventilator-induced lung injury and multiple system organ failure: a critical review of facts and hypotheses. Intensive Care Med 30: 1865-1872, 2004. https://doi.org/10.1007/s00134-004-2363-9

RANIERI VM, SUTER PM, TORTORELLA C, DE TULLIO R, DAYER JM, BRIENZA A, BRUNO F, SLUTSKY AS: Effect of mechanical ventilation on inflammatory mediators in patients with acute respiratory distress syndrome: a randomized controlled trial. JAMA 282: 54-61, 1999. https://doi.org/10.1001/jama.282.1.54

REPESSE X, CHARRON C, VIEILLARD-BARON A: Acute cor pulmonale in ARDS: rationale for protecting the right ventricle. Chest 147: 259-265, 2015. https://doi.org/10.1378/chest.14-0877

RICCI F, CATOZZI C, MURGIA X, ROSA B, AMIDANI D, LORENZINI L, BIANCO F, RIVETTI C, CATINELLA S, Villetti G, CIVElli M, PIOSElli B, DANI C, SAlOMONE F: Physiological, biochemical, and biophysical characterization of the lung-lavaged spontaneously-breathing rabbit as a model for respiratory distress syndrome. PLoS One 12: e0169190, 2017. https://doi.org/10.1371/journal.pone.0169190

RIVARA MB, BAJWA EK, JANUZZI JL, GONG MN, THOMPSON BT, CHRISTIANI DC: Prognostic significance of elevated cardiac troponin-T levels in acute respiratory distress syndrome patients. PLoS One 7: e40515, 2012. https://doi.org/10.1371/journal.pone.0040515

ROCCO PR, PELOSI P: Pulmonary and extrapulmonary acute respiratory distress syndrome: myth or reality? Curr Opin Crit Care 14: 50-55, 2008. https://doi.org/10.1097/MCC.0b013e3282f2405b

SALVESEN B, STENVIK J, ROSSETTI C, SAUGSTAD OD, ESPEVIK T, MOLLNES TE: Meconium-induced release of cytokines is mediated by the TRL4/MD-2 complex in a CD14-dependent manner. Mol Immunol 47: 1226-1234, 2010. https://doi.org/10.1016/j.molimm.2009.12.015

SILVA PL, PELOSI P, ROCCO PRM: Personalized pharmacological therapy for ARDS: a light at the end of the tunnel. Expert Opin Investig Drugs 29: 49-61, 2020. https://doi.org/10.1080/13543784.2020.1699531

SLUTSKY AS, TREMBLAY LN: Multiple system organ failure. Is mechanical ventilation a contributing factor? Am J Respir Crit Care Med 157: 1721-1725, 1998. https://doi.org/10.1164/ajrccm.157.6.9709092 
SUAREZ G, MEYERROSE G: Heart failure and galectin 3. Ann Transl Med 2: 86, 2014. https://doi.org/10.3978/j.issn.2305-5839.2014.09.10

SZYMANKIEWICZ M, GADZINOWSKI J, KOWALSKA K: Pulmonary function after surfactant lung lavage followed by surfactant administration in infants with severe meconium aspiration syndrome. J Matern Fetal Neonatal Med 16: 125-130, 2004. https://doi.org/10.1080/jmf.16.2.125.130

TASAKA S, AMAYA F, HASHIMOTO S, ISHIZAKA A: Roles of oxidants and redox signaling in the pathogenesis of acute respiratory distress syndrome. Antioxid Redox Signal 10: 739-753, 2008. https://doi.org/10.1089/ars.2007.1940

THOMAS AM, SCHJALM C, NILSSON PH, LINDENSKOV PHH, RORTVEIT R, SOLBERG R, SAUGSTAD OD, BERGLUND MM, STROMBERG P, LAU C, ESPEVIK T, JANSEN JH, CASTELLHEIM A, MOLLNES TE, BARRATT-DUE A: Combined inhibition of C5 and CD14 attenuates systemic inflammation in a piglet model of meconium aspiration syndrome. Neonatology 113: 322-330, 2018. https://doi.org/10.1159/000486542

ZEBIALOWICZ AHLSTROM J, MASSARO F, MIKOLKA P, FEINSTEIN R, PERCHIAZZI G, BASABE-BURGOS O, CURSTEDT T, LARSSON A, JOHANSSON J, RISING A: Synthetic surfactant with a recombinant surfactant protein $\mathrm{C}$ analogue improves lung function and attenuates inflammation in a model of acute respiratory distress syndrome in adult rabbits. Respir Res 20: 245, 2019. https://doi.org/10.1186/s12931-019-1220-x

ZEMANS RL, COLGAN SP, DOWNEY GP: Transepithelial migration of neutrophils: mechanisms and implications for acute lung injury. Am J Respir Cell Mol Biol 40: 519-535, 2009. https://doi.org/10.1165/rcmb.2008-0348TR 